\title{
Cost Benefit Analysis Management of Jerry Can Hemodialysis Used Packaging of Hazardous and Toxic Substances In The Islamic Hospital Surabaya
}

\author{
Putri Alfiani Nur Hanifah
}

S1 Administrasi Rumah Sakit STIKES Yayasan RS. Dr. Soetomo, JI. Prof. Dr. Moestopo 8A, Airlangga, Gubeng, Surabaya Jawa Timur 60286

Email: palfiani14@gmail.com

\begin{abstract}
Abstrak
Pengelolaan jirigen hemodialisa di Rumah Sakit Islam Surabaya secara pengangkutan dan pemusnahan terjadi kenaikan nilai kontrak sebesar $50 \%$ dan tidak efisien untuk dilanjutkan. Dengan adanya penawaran untuk pengelolaan jirigen hemodialisa secara Reduce, Reuse, Recycle (3R) maka penelitian ini bertujuan untuk menganlisis biaya dan manfaat (cost benefit analysis) pada pengelolaan jirigen hemodialisa pengangkutan dan pemusnahan dan pengelolaan jirigen hemodialisa secara Reduce, Reuse, Recycle (3R). Penelitian ini menggunakan metode cost benefit analysis yang merupakan penelitian kuantitatif dan bersifat observasional. Dari hasil perhitungan masing - masing pengelolaan jirigen hemodialisa didapatkan hasil Present Value (PV) cost untuk pengelolaan jirigen hemodialisa pengangkutan dan pemusnahan sebesar $\mathrm{Rp}$. 268.326.525 sedangkan PV cost pengelolaan jirigen hemodialisa reuse, reduce, recycle sebesar $\mathrm{Rp}$. 32.159.233. Untuk PV benefit pengangkutan dan pemusnahan adalah Rp. 0 dan PV benefit $3 \mathrm{R}$ adalah 97.015.367. Ratio B/C pengelolaan jirigen hemodialisa pengangkutan dan pemusnahan adalah 0 dan Ratio B/C secara 3R adalah 3,02. Berdasarkan nett present value diperoleh pengangkutan dan pemusnahan sebesar Rp. (-) 268.326 .525 sedangkan 3R sebesar Rp. (+) 64.856.134. Sehingga pengelolaan jirigen hemodialisa secara reduce, reuse, recycle yang lebih menguntungkan daripada pengelolaan jirigen hemodialisa secara pengangkutan dan pemusnahan. Dengan alasan pengelolaan jirigen hemodialisa secara reduce, reuse, recycle dapat menurunkan biaya pengeluaran rumah sakit serta menciptakan budaya ramah lingkungan.

Kata Kunci : Pengelolaan, Jirigen Hemodialisa, Cost Benefit Analysis
\end{abstract}

\section{Cost Benefit Analysis Management of Jerry Can Hemodialysis Used Packaging of Hazardous and Toxic Substances In The Islamic Hospital Surabaya}

\begin{abstract}
Management of jerry can hemodialysis at Islamic Hospital Surabaya by conveyance and extermination an increase contract value of $50 \%$ and not efficient for continously. With an offer for management of jerry can hemodialysis with Reduce, Reuse and Recycle (3R) method, then this research to intend for cost benefit analyze on management of jerry can hemodialysis conveyance and extermination method with management of jerry can hemodialysis Reduce, Reuse, and Recycle (3R) method. This research uses cost benefit analyze method which is qualitative research and observational nature. The result calculationts from each management of jerry can hemodialysis has been obtained Present Value (PV) cost for management of jerry can hemodialysis
\end{abstract}


conveyance and extermination method of 28.326.525 IDR, while Present Value (PV) cost with 3R method of 32.159.233 IDR. Preset Value benefit forconveyance and extermination is 0 IDR and Present Value benefit for $3 R$ Method is 97.015.367 IDR. Ratio B/C management of jerry can hemodialysis conveyance and extermination method is 0 and Ratio $B / C$ management with $3 R$ method is 3,02 . Based on nett present value for conveyance and extermination method has obtained (-) 268.326.525 IDR for while with 3R method is (+) 64.856.134 IDR. The conclusion is management of jerry canhemodialysis with $3 R$ method very profitable than management of jerry can hemodialysis with conveyance and extermination method. With reason management of jerry can hemodialysis with $3 R$ method can reduce hospital cost and creating an friendly environtment culture.

Keywords : Management, Jerry Can of Hemodialysis, Cost Benefit Analyze

Received: 10/08/2019; published: 01/10/2019

\section{PENDAHULUAN}

Rumah sakit sebagai tempat pemberi pelayanan kesehatan tidak terlepas dari limbah, baik limbah medis maupun limbah non medis, limbah padat maupun cair yang berbahaya bagi kesehatan masyarakat dirumah sakit atau sekitar lingkungan rumah sakit. Limbah B3 merupakan sisa suatu usaha atau kegiatan yang mengandung bahan berbahaya beracun. Jenis limbah B3 yang dihasilkan di rumah sakit meliputi limbah medis, baterai bekas, obat dan bahan farmasi kadaluwarsa, oli bekas, saringan oli bekas, lampu bekas, baterai, cairan fixer dan developer, wadah cat bekas (untuk cat yg mengandung zat toksik), wadah bekas bahan kimia, catridge printer bekas, film rontgen bekas, motherboard komputer bekas, dan lainnya. Limbah B3 yang dihasilkan rumah sakit dapat menyebabkan gangguan perlindungan kesehatan dan atau risiko pencemaran terhadap lingkungan hidup. Mengingat besarnya dampak negatif limbah B3 yang ditimbulkan, maka penanganan limbah B3 harus dilaksanakan secara tepat, mulai dari tahap pewadahan, tahap pengangkutan, tahap penyimpanan sementara sampai dengan tahap pengolahan (PMK No 7, 2019).

Rumah sakit merupakan fasilitas pelayanan kesehatan sebagaimana wajib melakukan pengelolaan limbah B3 yang meliputi pengurangan dan pemilahan limbah B3, penyimpanan limbah B3, pengangkutan limbah B3, pengolahan limbah B3, penguburan limbah B3, dan atau penimbunan limbah B3 (PerMenLHK 56, 2015). 75\%-90\% limbah kesehatan berupa limbah domestik, sedangkan 10\%-25\% limbah yang dihasilkan merupakan limbah yang berbahaya yang dapat merusak lingkungan dan berisiko terhadap kesehatan. Di Indonesia 
limbah padat yang dihasilkan dari 2,1-3,2 kg/tempat tidur/hari atau 10-23\% adalah berupa limbah medis padat (WHO, 2013). Menurut penelitian yang dilakukan di Brookdale University Hospital and Medical Center pada tahun 2017 menyimpulkan bahwa $70-80 \%$ limbah infeksius dari rumah sakit merupakan limbah non infeksius yang tercampur dengan limbah infeksius akibat pengelolaan yang buruk. Pengelolaan limbah B3 yang tidak dikelola dengan baik dapat mengakibatkan cidera, pencemaran lingkungan, serta penyakit nosokomial maka pengelolaannya harus diperlakukan secara khusus.

Di Rumah Sakit Islam Surabaya limbah dari jirigen bekas yaitu berasal dari unit Hemodialisa atau unit cuci darah. Limbah jirigen bekas HD terdiri dari jenis jerigen ukuran $5 \mathrm{~L}$ yang berisi cairan acid. Jumlah limbah jirigen HD yang terkumpul setiap harinya 5 buah-15 buah. Kandungan bahan yang ada didalam jirigen HD adalah cairan acid seperti cairan yang ada dalam cairan infus. Cairan yang ada didalam jirigen ini tidak tergolong dalam limbah B3 apabila tidak mengenai pasien, sedangkan apabila ada kontak langsung dengan pasien maka menjadi kategori limbah B3 (Agustin, Suyanto, \& Amri, 2017). Jika jirigen HD ini dilakukan pengangkutan dan pemusnahan pihak seksi Kesehatan Lingkungan membayar sebesar Rp. 14.850/kg sesuai dengan nilai kontrak dan perjanjian yang telah disepakati dan mengikuti harga investasi, operasional, pemeliharaan, dan fasilitas pendukung. Mengingat Rumah Sakit Islam A. Yani Surabaya tidak memiliki incinerator yang memadai serta letak rumah sakit yang berdekatan dengan sekolah dan permukiman warga sehingga pihak Rumah Sakit Islam A. Yani Surabaya bekerja sama dengan pihak ketiga yang sudah terpercaya dan memiliki legalitas dari $\mathrm{KLH}$.

\section{BAHAN DAN METODE}

Penelitian ini merupakan penelitian kuantitatif yang bersifat observasional deskriptif karena merupakan penelitian dengan studi analisis biaya, dengan cara membandingkan biaya (cost) dengan manfaat (benefit) dari program pengelolaan jirigen HD dengan metode Cost Benefit Analysis. Sedangkan berdasarkan waktunya, penelitian ini tergolong penelitian cross sectional karena penelitian ini dilakukan dalam suatu periode waktu tertentu. 
Pengambilan sampel dalam penelitian ini yaitu dengan mengidentifikasi semua unsur-unsur biaya yang diperlukan untuk pengelolaan jirigen HD pengangkutan dan pemusnahan dengan pengelolaan jirigen HD secara Reuse, Reduce, Recycle (3R). Metode pengumpulan data yang digunakan penulis dalam penelitian ini adalah dokumentasi. Dokumen merupakan catatan peristiwa yang sudah berlalu, yang berbentuk tulisan misalnya: catatan harian, sejarah kehidupan, cerita, biografi, peraturan, atau kebijakan (Sugiyono, 2013). Adapun data dokumen biaya pengelolaan jirigen HD secara pengangkutan dan pemusnahan dan secara 3R diperoleh dari logbook limbah B3, dari kwitansi biaya pengeluaran LB3 yang dimiliki oleh Seksi Kesehatan Lingkungan Rumah Sakit Islam A. Yani Surabaya. Metode penyajian data dalam penelitian ini dilakukan dengan langkah perhitungan sesuai dengan tahapan Cost Benefit Analysis. Data disajikan dalam bentuk tabel cost benefit analysis untuk mempermudah pembacaan data dan analisis hasil.

\section{HASIL DAN PEMBAHASAN}

Berdasarkan data perhitungan nilai cost dan benefit pengelolaan jirigen HD secara pengangkutan dan pemusnahan maupun secara $3 R$ dapat diketahui ratio antara PV costdan PV benefit sebagai berikut:

Tabel 1 Ratio Present Value (PV) Costdan Benefit $\begin{array}{llll}\text { Pengelolaan Jirigen HD } & \text { PV Benefit } & \text { PV Cost } & \text { Ratio B/C }\end{array}$

\begin{tabular}{lccc}
\hline Pengangkutan dan Pemusnahan & 0 & 268326525 & 0 \\
Secara 3R & 97015367 & 32159233 & 3,02 \\
\hline
\end{tabular}

Berdasarkan tabel diatas dapat diketahui nilai sekarang (present value) manfaat dari pengelolaan jirigen HD baik secara pengangkutan dan pemusnahan maupun secara 3R dalam tahun-tahun yang akan datang. Manfaat ditahun yang akan datang pada pengelolaan jirigen HD secara pengangkutan dan pemusnahan lebih kecil dari pengelolaan jirigen HD secara 3R. Hal ini dapat dilihat bahwa PV benefit pengelolaan jirigen HD pengangkutan dan pemunahan sebesar Rp. 0 sedangkan PV benefit secara 3R sebesar Rp. 97.015.367,. Untuk biaya yang banyak dibutuhkan adalah pada pengelolaan jirigen HD secara pengangkutan dan pemusnahan sebesar PV cost Rp. 268.326.525,. sedangkan 
untuk PV cost pengelolaan jirigen HD secara 3R sebesar Rp. 32.159.233,. Dari perbanding PV benefit dan PV cost pada kedua pengelolaan maka dapat diketahui bahwa nilai ratio $\mathrm{B} / \mathrm{C}$ pada pengelolaan jirigen $\mathrm{HD}$ pengangkutan adalah 0 sedangkan ratio $B / C$ pada pengelolaan jirigen $H D$ secara $3 R$ adalah 3,02. Angka tersebut diperoleh dari angka PV benefit dibagi dengan PV cost.

Berdasarkan perhitungan present value pada masing-masing pengelolaan jirigen HD didapatkan nilai Nett Present Value (NPV) sebagai berikut:

Tabel 2 Nett Present Value

\begin{tabular}{lccc}
\hline Pengelolaan Jirigen HD & PV Benefit & PV Cost & NPV (Rp) \\
\hline $\begin{array}{l}\text { Pengangkutan dan } \\
\text { Pemusnahan }\end{array}$ & 0 & 268.326 .525 & $(-) 268.326 .525$ \\
Secara 3R & 97.015 .367 & 32.159 .233 & $(+) 64.856 .134$ \\
\hline \multicolumn{1}{l}{ Berdasarkan tabel diatas bahwa NPV pengelolaan jirigen HD secara }
\end{tabular}

pengangkutan dan pemusnahan menunjukkan hasil negatif, artinya tidak adanya benefit atau benefit tidak cukup untuk menutup cost selama proyek berjalan 10 tahun kedepan nantinya sehingga proyek unfovourable. Sedangkan NPV pengelolaan jirigen HD secara 3R menunjukkan hasil positif, artinya benefit lebih besar dari cost selama proyek tersebut berjalan hingga 10 tahun kedepan sehingga disebut fovourable. Hasil tersebut diperoleh dari angka PV benefit dikurangi dengan angka PV cost.

Komponen cost pada pengelolaan ini yaitu biaya yang dikeluarkan oleh Seksi Kesehatan Lingkungan Rumah Sakit Islam Surabaya setiap bulannya pada tahun 2018 yang dimulai bulan Januari - Desember kepada pihak ketiga sebesar Rp. 14.850/kg. Komponen benefit dalam pengelolaan secara pengangkutan dan pemusnahan yaitu terkelolanya jirigen hemodialisa dengan cara di incinerator oleh pihak ketiga yang bekerja sama dengan Seksi Kesehatan Lingkungan sedangkan benefit rupiah nya ada Rp. 0 ,.

Dari hasil hitungan cost benefit analysis, diperoleh ratio $\mathrm{B} / \mathrm{C}$ pada pengelolaan jirigen hemodialisa secara pengangkutan dan pemusnahan adalah 0 . Angka tersebut diperoleh dari angka PV benefit dibagi dengan PV cost. Hasil dari ratio $\mathrm{B} / \mathrm{C}$ menunjukkan bahwa cost yang dikeluarkan lebih besar daripada benefit yang diperoleh. Dari pengurangan antara total PV benefit dan total PV cost didapatkan nilai nett present value (NPV). Pada pengelolaan secara pengangkutan dan pemusnahan NPV menunjukkan hasil negatif yaitu Rp. (-) 
268.326.525 yang berarti proyek tersebut jika diteruskan unfovourable yang artinya benefit tidak cukup untuk menutupi cost + investment selama umur teknis ekonomis proyek yaitu 10 tahun.

Pengelolaan jirigen hemodialisa secara 3R merupakan penyerahan jirigen terhadap pihak ketiga untuk di reuse, reduce, recycle untuk keperluan usaha produksi salah satunya yaitu timba cor. Kerja sama dengan Seksi Kesehatan Lingkungan Rumah Sakit Islam Surabaya dimulai dari bulan Januari tahun 2019 hingga sampai saat ini. Komponen cost dan benefit pada pengelolaan jirigen secara 3R bersifat tangible (berwujud uang).

Komponen cost terdiri dari biaya gaji 2 orang untuk mencacah atau memotong jirigen, biaya untuk membeli desinfektan seberat 2.160 gram pada setiap bulan dari bulan Januari-Juni, membeli alat pemotong atau pencacah yaitu pisau khusus yang sudah dibeli sebanyak 2 buah setiap 2 bulan sekali, dan membayar biaya air $1,8 \mathrm{~m}^{3}$ yang telah digunakan dalam proses pensterilan jirigen. Komponen benefit pada pengelolaan jirigen hemodialisa secara 3R sebesar Rp. 6.000/kg yang diterima Seksi Kesehatan Lingkungan setiap bulannya sesuai dengan timbangan bersih jirigen hemodialisa yang sudah disterilkan.

Dalam perhitungan cost benefit analysis, diperoleh ratio B/C pengelolaan jirigen hemodialisa secara 3R sebesar 3,02. Angka tersebut diperoleh dari angka PV benefit dibagi dengan PV cost. Hasil ratio B/C menunjukkan bahwa benefit yang diterima lebih besar dari cost yang dikeluarkan. Dari pengurangan antara total PV benefit dan total PV cost didapatkan nilai nett present value. Pada pengelolaan jirigen HD secara $3 R$ hasil NPV nya adalah hasil positif yaitu sebesar Rp. (+) 64.856.134 yang berarti proyek tersebut favourable atau pengelolaan jirigen HD secara 3R dapat dilakukan perluasan dan dilakukan perbaikan dalam setiap alur pengelolaannya.

Dari hasil perhitungan ratio $\mathrm{B} / \mathrm{C}$, diperoleh bahwa ratio $\mathrm{B} / \mathrm{C}$ pada pengelolaan jirigen HD secara pengangkutan dan pemusnahan lebih kecil yaitu 0 daripada pengelolaan jirigen HD secara $3 R$ yaitu 3,02. Selain itu hasil dari perhitungan NPV, nilai NPV pada pengelolaan jirigen HD secara pengangkutan dan pemusnahan menunjukkan negatif, maka pada penelitian ini diperoleh pengelolaan jirigen HD secara 3R lebih menguntungkan untuk dilaksanakan dibandingkan pengelolaan jirigen HD secara pengangkutan dan pemusnahan. 
Alasan peneliti memilih nilai present value atau memprediksi komponen cost dan benefit hingga 10 tahun yaitu karena jumlah kunjungan di Unit Hemodialisa Rumah Sakit Islam Surabaya terjadi peningkatan yang cukup signifikan, hal itu menyebabkan jumlah $\mathrm{kg}$ jirigen HD juga terjadi peningkatan. Semakin banyak jirigen HD yang dilakukan $3 R$ maka benefit rupiah yang didapatkan oleh pihak Seksi Kesehatan Lingkungan Rumah Sakit Islam Surabaya juga semakin menguntungkan. Selain itu pihak manajemen juga harus memperhatikan Undang-Undang, Peraturan Menteri maupun Peraturan Pemerintah yang mengatur tentang pengelolaan Limbah B3 dan Kesehatan Lingkungan Rumah Sakit. Sesuai dengan peraturan per Undang-Undang perusahaan atau pihak ketiga yang bekerja sama harus memiliki posisi yang kuat (berbadan hukum) untuk melihat risiko dan mempermudah dilakukannya tuntutan hukum jika terjadi hal yang merugikan salah satu pihak. Pihak ketiga juga harus memiliki reputasi yang bagus, ahli dibidangnya, serta memiliki kualitas yang sesuai dengan harapan manajemen.

Terdapat beberapa alasan yang mengarahkan para manajer pelayanan kesehatan memilih untuk bekerja sama dengan pihak ketiga yaitu untuk alasan finansial, operasional, bahkan untuk lingkungan. Melalui kerja sama dengan pihak ketiga pengelolaan jirigen HD secara $3 R$ rumah sakit ikut serta melaksanakan prinsip green hospital yaitu menerapkan upaya pengurangan, penggunaan kembali, daur ulang dan composting dari limbah yang dihasilkan. Penggunaan incinerator untuk memusnahkan limbah hanya sebagai alternatif terakhir, serta rumah sakit melaksanakan sistem manajemen rumah sakit yang ramah lingkungan.

Selain itu keuntungan melaksanakan pengelolaan jirigen HD secara $3 R$ dari aspek kesehatan yaitu dapat menurunkan kasus infeksi, dari aspek ekonomi dapat mengurangi biaya pengeluaran dari pengelolaan jirigen HD pengangkutan dan pemusnahan agar biaya pengeluaran dapat dimanfaatkan untuk kegiatan lain yang lebih menguntungkan, dari aspek sosial rumah sakit dapat meningkatkan citra positif dalam tahapan melakukan pemenuhan standar green hospital, sedangkan dari aspek lingkungan secara tidak langsung memperkecil dampak negatif dari asap yang dihasilkan incinerator. Namun yang tetap harus diperhatikan oleh pihak manajemen yaitu pekerja yang melakukan proses pencacahan dan pensterilan wajib menggunakan APD. 
Secara sosial pengelolaan jirigen hemodialisa secara 3R jika sudah dilakukan pencacahan menggunakan mesin akan menimbulkan kebisingan bagi pasien rawat inap dan pengunjung rumah sakit maka pihak Rumah Sakit Islam Surabaya harus mengantisipasi keadaan dengan meminimalisasi kebisingan tersebut dan menimbulkan rasa nyaman suasana penyembuhan serta menciptakan interaksi sosial yang positif dilingkungan rumah sakit. Secara ekonomis pengelolaan jirigen hemodialisa secara 3R yang lebih menguntungkan untuk tetap dilaksanakan yang perlu diperhatikan oleh pihak manajemen yaitu memfasilitasi Seksi Kesehatan Lingkungan dengan membangunkan TPS 3R dan menjamin perlindungan masyarakat rumah sakit dari ancaman infeksi atau masalah kesehatan yang berdampak terhadap minimalisasi biaya pemeliharaan kesehatan yang harus disediakan. Pihak manajemen Rumah Sakit Islam Surabaya atau Seksi Kesehatan Lingkungan melakukan pengawasan terhadap pihak ketiga yang melakukan pengelolaan jirigen hemodialisa secara 3R dalam waktu penimbangan setelah proses pencacahan dan pensterilan. Sebaiknya jirigen hemodialisa yang telah dilakukan pencacahan dan pensterilan tidak langsung dimasukkan ke dalam kantong plastik agar ditiriskan terlebih dahulu untuk menghindari kesalahan dalam penimbangan.

\section{SIMPULAN DAN SARAN}

Komponen cost pengelolaan jirigen hemodialisa secara pengangkutan dan pemusnahan terdiri dari biaya pengeluaran. Dalam komponen benefit pada pengelolaan ini yaitu terkelolanya jirigen HD dan benefit ( $R p)$ yang didapat adalah Rp. 0,. Sedangkan komponen cost untuk pengelolaan jirigen hemodialisa secara $3 R$ yaitu berupa biaya gaji untuk 2 orang, biaya untuk membeli desinfektan dan pisau, serta membayar air 1,8 $\mathrm{m}^{3}$. Dalam komponen benefit pada pengelolaan ini terkelolanya jirigen hemodialisa dan benefit $(\mathrm{Rp})$ nya sebesar $\mathrm{Rp}$. $6000 / \mathrm{kg}$. Pada pengelolaan jirigen HD secara pengangkutan dan pemusnahan dalam 10 tahun diperoleh PV benefit Rp. 0,. dengan PV cost sebesar 268.326.525,. sedangkan pada pengelolaan jirigen HD secara reduce, reuse, recycle dalam 10 tahun diperoleh PV benefit Rp 97.015.367,. dengan PV cost yang dikeluarkan sebesar Rp. 32.159.233,. Ratio B/C pengelolaan jirigen secara pengangkutan dan pemusnahan adalah 0 dan ratio $B / C$ pengelolaan jirigen HD secara $3 R$ adalah 3,02. Diperoleh nett present value pengelolaan jirigen HD 
secara pengangkutan dan pemusnahan menunjukkan hasil negatif yaitu sebesar Rp. (-) 268.326.525,. sedangkan pengelolaan jirigen HD secara 3R menunjukkan hasil positif sebesar Rp. (+) 64.856.134,. Pengelolaan jirigen HD secara 3R lebih menguntungkan untuk dilaksanakan dibandingkan dengan pengelolaan jirigen $\mathrm{HD}$ secara pengangkutan dan pemusnahan dengan pertimbangan ratio $\mathrm{B} / \mathrm{C}$ dan nilai NPV pengelolaan jirigen HD secara $3 R$ yang menunjukkan hasil positif.

\section{DAFTAR PUSTAKA}

1. 101, P. Peraturan Pemerintah RI No 101 tentang Pengelolaan Limbah Bahan Berbahaya Beracun. 2014.

2. Agustin, C. R., Suyanto, A., \& Amri, C. Pemaanfaatan Limbah Jerigen Menjadi Safety Box Di Rsud Wates, Tahun 2016. Sanitasi: Jurnal Kesehatan Lingkungan, 8(4), 158. https://doi.org/10.29238/sanitasi.v8i4.66. 2017

3. Dewi, C. A. Pengelolaan Limbah Medis Padat Di Rumah Sakit Umum Daerah Kelet Kabupaten Jepara. Retrieved from http://lib.unnes.ac.id/20215/1/6450408063.pdf. 2014.

4. Indrayathi, P. A. Bahan Ajar Economic Evaluation in Health Care. Universitas Udayana. 2016.

5. Kemenkes RI. Permenkes RI No 56 Tahun 2014 tentang Perizinan dan Klasifikasi RS. (879), 2004-2006. Retrieved from www.peraturan.go.id. 2014.

6. Lingkungan, M., Dan, H., \& Republik, K. (2016). Berita Negara. (2118).2016.

7. Manajemen, J., Stikes, K., \& Rs, Y. No Title. 2(2), 143-152. 2016.

8. Pengantar, K. Direktorat Fasilitas Pelayanan Kesehatan Direktorat Jenderal Pelayanan Kesehatan Kementerian Kesehatan Republik Indonesia Tahun Pedoman Green Hospital. 2018.

9. Purwohandoyo, A. Analisis Perbandingan Biaya Pengelolaan Limbah Medis Padat Antara Sistem Swakelola dengan Sistem Outsourcing di Rumah Sakit Kanker Dharmais. Jurnal Administrasi Rumah Sakit Indonesia, 2(3), 183-193. https://doi.org/10.7454/ARSI.V2I3.2206. 2018.

10. Republik, mentri kesehatan. (n.d.). Keputusan Mentri Kesehatan Republik Indonesia Nomor 1204/Menkes/Sk/X/2004.Pdf.

11. Sakit, R., Husada, A., \& Surabaya, K. Cost Benefit Analysis Pada Unit Pencucian Linen Outsourcing. 2010.

12. Turkheimer, E., \& Waldron, M. 2019. PMK NO 7, Psychological Bulletin, 
126(1), 21. https://doi.org/.1037//0033-2909.I26.1.78. 2019.

13. Undang, U., Sampah, P., \& Tahun, N. Waste Management Program In Indonesia.2008.

14. www.hukumonline.com. Undang - Undang Republik Indonesia No 44 Tahun 2009 tentang Rumah Sakit. 2009. 